\title{
ENEGRECENDO AS REFERÊNCIAS: INTERVENÇÕES POSSÍVEIS DO MOVIMENTO NEGRO NA EDUCAÇÃO BRASILEIRA
}

\author{
Monalisa Aparecida do CARMO \\ Universidade Estadual de Campinas (UNICAMP), Campinas, São Paulo, Brasil, Universidade \\ Federal de Viçosa (UFV), Viçosa, Minas Gerais, Brasil \\ BeAtriz GOMEs CoRnélIO \\ Universidade Federal de Viçosa (UFV), Viçosa, Minas Gerais, Brasil \\ LILLIAN FERREIRA RODRIGUES \\ Universidade Federal de Viçosa (UFV), Viçosa, Minas Gerais, Brasil \\ Matheus Silva Freitas \\ Universidade Federal de Minas Gerais (UFMG), Belo Horizonte, Minas Gerais, Brasil
}

\begin{abstract}
Resumo: Este artigo busca apresentar algumas contribuições do Movimento Negro brasileiro para a educação, a partir das experiências e dos diálogos tecidos na realização do minicurso: "Enegrecendo as referências: epistemicídio, descolonização e intelectuais negras/os". Por meio do relato de experiência e da revisão bibliográfica, procuramos analisar possíveis formas de intervenção do Movimento Negro na educação e o minicurso enquanto materialização das discussões para enfrentar o apagamento de intelectuais negras/os das referências bibliográficas. Constatamos que, com a entrada de sujeitos negros nas universidades e a necessidade de reconhecer e valorizar a história e cultura afrobrasileira no âmbito educacional, há um tensionamento nos/dos referenciais lidos, citados e refletidos, e que os diálogos produzidos pelo minicurso apontam a necessidade da construção de uma educação antirracista.
\end{abstract}

Palavras-chave: Movimento Negro. Educação. Epistemicídio.

\section{INTRODUÇÃO}

Este trabalho se constituiu a partir do incômodo diante do apagamento de referências negras na construção de conhecimentos no ensino superior brasileiro. Pensamos que "enegrecer" diferentes movimentos, processos e ambientes é uma demanda constante das empreitadas antirracistas. Mobilizadas pelas reivindicações e conquistas do Movimento Negro no campo educacional, o Grupo de Estudos em Educação, Gênero e Raça - Educagera propôs a realização do minicurso intitulado "Enegrecendo as referências: epistemicídio, descolonização e intelectuais negras/os", durante o Simpósio de Integração Acadêmica (SIA ${ }^{1}$, realizado no Campus Viçosa da Universidade Federal de Viçosa (UFV), em outubro de 2019.

As afetações experienciadas antes e durante esse curso nos conduziram para a construção do presente artigo. Dessa forma, o nosso objetivo é compreender como as 
lutas do Movimento Negro no Brasil, ao eleger a educação formal como uma das dimensões importantes para a promoção da igualdade racial e combate ao racismo, constroem demandas e conquistas que possibilitam questionar a ausência e (in)visibilidade da produção de conhecimentos de intelectuais negras/os e, portanto, de combater o epistemicídio e enegrecer as referências no ensino superior brasileiro.

Sabemos que o racismo promove uma série de desigualdades e discriminações contra a população negra, inferiorizando-a em aspectos sociais, econômicos, psicológicos, emocionais etc., além de interferir e atravessar a construção e difusão dos conhecimentos, dentre eles, o científico. Por esse ângulo, segundo Renato Noguera (2015, on-line) o racismo também é epistêmico, pois há uma "recusa em reconhecer que a produção de conhecimento de algumas pessoas seja válida" e isso se dá por, ao menos, duas razões: primeiro, pelo fato dessas pessoas não serem brancas e, segundo, porque, na maior parte das vezes, seus conhecimentos "não envolvem repertórios e cânones que não são ocidentais" (NOGUERA, 2015, on-line).

A dominação colonial e racial, portanto, também é epistemológica. Ângela Figueiredo e Ramon Grosfoguel (2009) destacam que na geopolítica do conhecimento, "a perspectiva particular do homem branco se ergue como norma universal" (FIGUEIREDO, GROSFOGUEL, 2009, p. 228). Desse modo, todo o conhecimento produzido por populações que destoam das características dominantes e hegemônicas de sexo/gênero masculino e raça branca é deslegitimado em uma constante produção de não existência.

A produção social do não existente envolve uma série de atitudes, desde a inferiorização, invisibilidade, desaprovação até a completa morte do conhecimento. Isto é, o epistemicídio, que segundo Sueli Carneiro (2005) é elaborado de forma estratégica e complexa:

\begin{abstract}
O epistemicídio é, para além da anulação e desqualificação do conhecimento dos povos subjugados, um processo persistente de produção da indigência cultural: pela negação ao acesso à educação, sobretudo de qualidade; pela produção da inferiorização intelectual; pelos diferentes mecanismos de deslegitimação do negro como portador e produtor de conhecimento e de rebaixamento da capacidade cognitiva pela carência material e/ou pelo comprometimento da auto-estima pelos processos de discriminação correntes no processo educativo. Isto porque não é possível desqualificar as formas de conhecimento dos povos dominados sem desqualificá-los também, individual e coletivamente, como sujeitos cognoscentes. E, ao fazê-lo, destituiIhe a razão, a condição para alcançar o conhecimento "legítimo" ou legitimado. Por isso o epistemicídio fere de morte a racionalidade do subjugado ou a seqüestra, mutila a capacidade de aprender etc. (CARNEIRO, 2005, p. 97).
\end{abstract}

O epistemicídio, como tentativa de desconsiderar negras/os como produtores/as de conhecimento, arquiteta diversas formas de matar tal intelectualidade. Entendemos que as lutas do Movimento Negro, ao colocar a educação formal como uma 
CARMO, M. A. do; CORNÉLIO, B. G.; RODRIGUES, L. F.; FREITAS, M. S

dimensão fundamental para o combate ao racismo, também configura um enfrentamento ao epistemicídio.

Nesse sentido, é importante compreender como o Movimento Negro tem historicamente construído propostas para repensar a educação. Reivindicações e conquistas como as cotas para estudantes negras/os no ensino superior e o ensino da história e cultura afro-brasileira, africana e indígena na educação básica, tensionam e inquietam as universidades, indo desde a necessidade de currículos que atendam a diversidade de sujeitos que passam a frequentá-las às adaptações na formação de professores/as para atuar na educação escolar.

Tais transformações geram profundos questionamentos sobre a hegemonia de intelectuais brancos e a ausência das vozes negras nas bibliografias, sejam as vozes que compõem saberes acerca das relações étnico-raciais, sejam as das mais diversas áreas do conhecimento. Consequentemente, o Movimento Negro instiga a produção ressignificada das narrativas negras, o que demanda articulações com o Estado para intervir na estrutura educacional.

Buscando propostas para uma educação capaz de construir outras relações entre educadoras/es, pesquisadoras/es e referências bibliográficas, e ao requerer uma prática pedagógica antirracista, somos instigadas a entender: como a pauta educacional vem sendo construída pelo Movimento Negro? Quais medidas legais têm sido estabelecidas? Como a presença de estudantes negras/os no ensino superior reverbera ações para uma educação antirracista?

Para refletirmos sobre essas questões e relatar a experiência do minicurso, dividimos este artigo em duas partes centrais. Na próxima seção apresentamos brevemente as lutas do Movimento Negro no Brasil, chamando a atenção para suas reivindicações por educação formal, notadamente as ações que incidem nos currículos escolares e no acesso de negras/os ao ensino superior. Em seguida, relatamos a experiência do minicurso apontando algumas de suas dimensões teóricometodológicas.

\section{MOVIMENTO NEGRO PELA EDUCAÇÃO}

A consolidação do Movimento Negro brasileiro, integrado às ações políticas e sociais sob o efeito de requisições e da conquista de direitos, produz saberes que, ligados à educação, encontram vias de rompimento da influência ideológica dominante, hegemônica e eurocêntrica ditada pela branquitude ${ }^{3}$, visto que a ação desta acarreta o silenciamento e apagamento da existência e da produção intelectual negra. Em contraposição e resistência a esse processo, segundo Nilma Lino Gomes (2017), o Movimento Negro constitui-se a partir das

[...] mais diversas formas de organização e articulação das negras e dos negros politicamente posicionados na luta contra o racismo e que visam à superação desse perverso fenômeno da sociedade. Participam dessa definição os grupos políticos, culturais, religiosos e artísticos com o objetivo explícito de superação ao racismo e da discriminação racial, de valorização e afirmação da história e das culturas negras no Brasil, de rompimento das barreiras racistas impostas aos negros e às negras na ocupação dos diferentes 
espaços e lugares da sociedade (GOMES, 2017, p.23-24, grifos da autora).

Desse modo, ao se compor por diversos grupos da negritude, o Movimento Negro incorpora direta ou indiretamente aos sujeitos, a ética da convicção do antirracismo que, de acordo com Sales Augusto dos Santos (2011), delibera a luta em combate ao racismo em distintos âmbitos sociais, inibindo a difusão do ideário da democracia racial, a fim de promover a igualdade de direitos na sociedade. Assim, o Movimento Negro destaca-se por seu caráter educador, perpassando a dimensão coletiva e política na articulação entre os conhecimentos produzidos pela e/ou em prol da coletividade e as políticas públicas, assumindo uma perspectiva epistemológica antirracista e decolonial (GOMES, 2017).

$\mathrm{Na}$ historiografia brasileira, o desestruturado pós-abolição (1888) e a reestruturação da conjuntura política na República (1889), evidenciam o apagamento das negligências sociais, econômicas, políticas e culturais que seguem acometendo a população negra, banalizando o acesso ao que, em 1948, se constituiria, pela Declaração Universal dos Direitos Humanos, como direitos essenciais a todos os sujeitos no que tange à moradia, à saúde, ao trabalho, à integridade física e moral, à liberdade de expressão, ao acesso cultural e científico, dentre outros, sobretudo à educação.

Segundo Gomes (2017), o alcance do direito à educação por sujeitos negros apresentou um longo percurso até atingir a presente conformação. No período da escravização, e posteriormente, negras/os afro-brasileiras/os e africanas/os, na condição de escravizadas/os, ex-escravizadas/os ou livres, em menor ou maior grau, foram excluídas/os do acesso à educação formal, como destaca Marcus Fonseca (2016). Diante disso, o Movimento Negro assumiu o protagonismo na luta pela inserção dos sujeitos aos processos formais educacionais e na busca por políticas públicas capazes de reconhecer suas histórias e culturas.

Entre os séculos XIX e XX, algumas organizações do Movimento Negro, como a imprensa negra, a Frente Negra Brasileira (1931-1937) e o Teatro Experimental do Negro (1944-1968), assumiram uma postura educacional, engajada em informações de cunho político que contribuíram na produção de saberes e refletiram em reivindicações estruturadas, como projetos de leis consolidados e em tramitação, negados e restituídos (GOMES, 2017).

Em 1978, o surgimento do Movimento Negro Unificado também intensificou as discussões étnico-raciais centrando a educação entre os seus principais debates, contribuindo com a geração de conhecimentos emancipatórios e a construção política, social e educacional dos sujeitos e, consequentemente, estimulando a formação de intelectuais negras/os (SANTOS, 2011; GOMES, 2017).

Assim, as lutas do Movimento Negro trouxeram à educação a compreensão de que as políticas públicas devem estar atentas à situação social da população negra. Segundo Santos (2014, p. 180), as formas de combate e reação ao racismo, isto é, os antirracismos, são múltiplos, "requerendo não apenas uma, mas várias ações e políticas públicas e/ou privadas", justamente porque o racismo é difuso, dinâmico e constantemente renovado a partir das conjunturas históricas. 
Nesse sentido, o autor compreende que os movimentos negros, em especial nos governos comandados por Fernando Henrique Cardoso, Luiz Inácio Lula da Silva e Dilma Vana Rousseff, conquistaram maior abertura no Estado e construíram "políticas de promoção da igualdade racial", que podem ser definidas como ações de combate ao "racismo, o preconceito, a discriminação e as desigualdades raciais em todas as esferas da vida social", através de políticas universais ou específicas (SANTOS, 2014, p. 177).

Consoante às contribuições de Luciana Jaccoud e Nathalie Beghin (2002), Santos (2014, p. 177-178) entende que essas políticas, de forma geral, devem ser e são compostas simultaneamente por três tipos de ações: 1) as repressivas, sintetizadas na "proibição do racismo, conforme estabelece a nossa Constituição, e da punição de sua prática, de acordo com a legislação vigente"; 2) as valorizativas, que buscam a "valorização dos grupos raciais e étnicos que são discriminados", como negras/os e indígenas; e 3) as afirmativas, que objetivam "promover a igualdade de oportunidade, de tratamento, assim como promover a inclusão (por meio de acesso e permanência diferenciados) dos grupos discriminados racialmente em áreas onde eles são subrepresentados".

Amilcar Pereira, Jorge Maia e Thayara Lima (2020) chamam atenção para o fato de que, atualmente, militantes e ativistas do Movimento Negro veem as cotas para negras/os nas universidades públicas e a criação da lei 10.639/03 como as conquistas mais significativas da luta antirracista no Brasil. Desvelam que ambas "vem intervindo de forma significativa nas disputas em torno dos currículos escolares e universitários, e na educação de maneira geral" (PEREIRA et al., 2020, p. 173).

\section{LEI 10.639 E A CONSTRUÇÃO DE UMA EDUCAÇÃO ANTIRRACISTA}

As reivindicações historicamente construídas pelo Movimento Negro têm sido convertidas em políticas públicas, com ênfase no campo educacional, que tornou-se o principal meio de intervenção emancipatória determinada pelo movimento (GOMES, 2017). Dentre suas operações, acrescenta-se a ressignificação e a restituição de narrativas da historiografia brasileira, a começar pelo currículo da educação básica sob a obrigatoriedade do ensino da história e cultura afro-brasileira e africana pelas redes de ensino, segundo a lei no 10.639 de 9 de janeiro de 2003, modificada pela lei $n^{\circ} 11.645$, de 10 de março de 2008, em alteração à lei de Diretrizes e Bases da Educação (LDB/1996).

A medida supracitada rompe com a abordagem historiográfica tradicional e universal que, de acordo com Selva Fonseca (2008), direciona seu estudo às personalidades e aos acontecimentos dados como grandes, ou seja, o estudo dos denominados heróis e fatos ditos únicos e principais na história. Tal rompimento reporta ao século $\mathrm{XX}$, quando intelectuais passaram a perfilhar uma nova abordagem historiográfica capaz de envolver a diversidade social. Por meio desse processo, para além de sujeitos históricos, a historiografia passa a ouvir os espaços reivindicados também pelos movimentos sociais (FONSECA, 2008).

O papel da história na construção das identidades é reforçado e o Movimento Negro demanda espaço para a historiografia dos sujeitos negros, sendo que o caminho para tal intento é o acesso à educação. Logo, foi necessário reivindicar ao Estado brasileiro repensar a estrutura educacional e promover ações capazes de atravessar 
desde o currículo da educação básica e superior até a formação continuada de docentes em exercício.

Diante disso, a lei 10.639/03 considera que o currículo deve reverberar sua não neutralidade em desacordo com o padrão eurocêntrico, promovendo a releitura da estrutura educacional, permitindo a contextualização e interdisciplinaridade dos conteúdos. Assim, o desenvolvimento de metodologias antirracistas aplicadas à educação básica e superior direcionará teorias e práticas ao diálogo com as epistemologias que, além de impulsionar estudos voltados à história afro-brasileira e a proximidade entre África e Brasil, sustentará os processos emancipatórios e a construção de identidades afirmativas.

As diretrizes curriculares para a educação das relações étnico-raciais e para o ensino de história e cultura afro-brasileira e africana consideram que para as ações educativas de combate ao racismo, os estabelecimentos do ensino básico ao superior devem se articular com grupos dos movimentos sociais negros para, por exemplo, garantir suas presenças na formação de professores/as (SILVA, 2004). Dessa forma, mais do que reconhecer o Movimento Negro como demandante dessas políticas, assim como construtor em interface com o Estado, as entidades do Movimento Negro também devem ser consideradas para atuarem em sua implementação.

Nessa perspectiva, vale dizer que essa lei não visa apenas à inclusão de "mais" ou "novos" conteúdos nos currículos, mas de uma mudança e transformação sistêmica, epistemológica e política (GOMES, 2012, p. 106). De acordo com Petronilha Silva (2004), junto ao ensino de história e cultura afro-brasileira e indígena, desdobra-se a necessidade de uma educação das relações étnico-raciais que não consiste apenas em transformações nos componentes curriculares, mas que também promova mudanças nas relações interpessoais no ambiente escolar, incidindo na "reeducação das relações entre negros e brancos" (SILVA, 2004, p. 86).

Embora estejamos mencionando a história e cultura afro-brasileira e africana e o ensino das relações étnico-raciais, ressaltamos a necessidade de enegrecer as referências. Isso corresponde, em primeiro lugar, ao reconhecimento e valorização da contribuição dos povos negros como produtores e detentores de conhecimento, dentre eles, o científico. Em segundo lugar, mas não menos importante, a defesa da inclusão e presença de intelectuais negras/os que abordam diferentes temáticas em todas as áreas do conhecimento e não exclusivamente nas reflexões sobre relações étnico-raciais.

\section{TENSÕES E (PRO)POSIÇÕES AFIRMATIVAS NO ENSINO SUPERIOR}

Como afirmamos, todo o arcabouço constitucional e pedagógico que deriva da lei 10.639/03 impacta e tensiona diretamente a educação básica, assim como o ensino superior, em especial os cursos de licenciatura e formação de professores/as. A demanda pelo ensino de história da África e dos afro-brasileiros, junto às discussões sobre relações étnico-raciais, é traçada coetaneamente com a diversificação dos corpos discentes universitários.

Com a redemocratização do Brasil entre as décadas de 1980 e 1990, as questões raciais impulsionaram discussões sobre ações afirmativas, instigadas principalmente 
pelo projeto de lei $n^{\circ} 1.332 / 1983$, do então deputado federal Abdias Nascimento, que conferia ao projeto vias de ação compensatória diante das desigualdades vivenciadas por negras/os na sociedade brasileira desde o período colonial. Apesar da reprovação da proposta em votação no Congresso Nacional, ela foi fundamental para a verificação da realidade da população negra e a disseminação da concepção na qual políticas de ação afirmativa são fundamentais para ressarcir os danos causados pela estrutura racialmente desigual.

Embora a nível federal a reserva de vagas para negras/os e indígenas no ensino superior tenha sido instituída obrigatoriamente a partir de 2013, com a aprovação da lei 12.711/12, desde o início dos anos 2000 as universidades têm recebido um número maior, mas ainda muito limitado, desses/as estudantes, uma vez que diversas universidades passaram a aderir a algum tipo de ação afirmativa².

É necessário registrar que a lei $12.711 / 12$ instaura um sistema de cotas para estudantes de escola pública, com subcotas para pessoas de baixa renda e pretas/os, pardas/os e indígenas. ${ }^{4}$ Segundo Santos (2015), a legislação compreende as desigualdades econômicas como principais e "trata a discriminação e a desigualdade raciais como epifenômenos da questão de classe" (SANTOS, 2015, p. 76). A pesquisa de Vanessa da Silva $(2017$, p. 157) demonstra como no trâmite decisório de formulação dessa lei houve um "apagamento, silenciamento e supressão das ideias sócio-políticas das pessoas negras", fazendo com que a temática racial, central nas demandas e discussões das ações afirmativas no Brasil, fosse adensada de forma marginal como uma subcota. Com isso, observamos como o epistemicídio também atravessa a formulação das políticas de promoção da igualdade racial. Ademais, tal situação nos remete ao dilema de como as demandas e pressões de movimentos sociais negros passam a ser implementadas pelo Estado. Conforme demonstra Gomes (2017, p. 36), "o processo de implementação de tais leis e políticas [de promoção da igualdade racial] nem sempre corresponde à radicalidade emancipatória das reivindicações que o originaram".

De acordo com Daniel Mato (2018), a emergência de programas e ações direcionados aos povos indígenas e afrodescendentes na educação superior é uma realidade na América Latina. Vários países da região, após o período das ditaduras militares (em geral, das décadas de 1960 a 1980), foram palco de lutas e processos por democratização que estiveram sintetizados em suas reformas constitucionais que, em sua maior parte, garantiram direitos educativos e culturais dessas populações. $\mathrm{Na}$ atualidade, segundo Mato (2018), há um conjunto de experiências no ensino superior operacionalizadas por e para povos indígenas e afrodescendentes, que abrangem iniciativas de inclusão como as cotas, programas de formação criados especialmente para esses/as estudantes, projetos de ensino, pesquisa e extensão desenvolvidos pelas universidades com participação dessas comunidades e a criação de instituições de ensino superior interculturais.

Nesse contexto de democratização e diversificação do ensino superior, Mato (2018) assinala alguns desafios para essas ações na América Latina, sendo um deles a própria existência do racismo persistindo em outros arranjos.

\footnotetext{
Un problema es que en el siglo XXI el racismo no siempre se expresa de formas abiertas, sino solapadas; en muchos casos es inconsciente. (...) Hay otras, más sutiles, asociadas a la negación del valor de los conocimientos, lenguas, modos de producción de
} 


\begin{abstract}
conocimiento y modalidades de aprendizaje, valores, visiones de mundo, historias y propuestas de los pueblos indígenas y afrodescendientes. Esto se expresa en su exclusión de los planes de estudio en general y en las bibliografías de las asignaturas de la inmensa mayoría de las universidades y otros tipos de IES de la región, en todas las carreras (MATO, 2018, p. 66, grifos nosso) ${ }^{5}$.
\end{abstract}

Diante das formas de negação do conhecimento, o Movimento Negro no Brasil vem propiciando várias transformações no ensino superior e na sociedade brasileira ante a politização do racismo, a diversificação dos corpos discentes das universidades, assim como de mudanças e tensões na produção do conhecimento científico.

Para Gomes (2017), as políticas de ação afirmativa provocam a construção de saberes estético-corpóreos. Saberes estes que o movimento negro brasileiro sistematizou nos últimos anos, pois as juventudes negras que ingressam nas instituições de ensino superior a partir dessas políticas são "sujeitos sociais concretos com outros saberes, outra forma de construir o conhecimento acadêmico e com outra trajetória de vida, bem diferentes do tipo ideal de estudante universitário hegemônico e idealizado em nosso país" (GOMES, 2017, p. 114). Nesse sentido, podemos entender que as ações afirmativas compõem posturas e saberes emancipatórios que possibilitam questionar discriminações e desigualdades raciais nas universidades e na sociedade de forma geral.

Para Joana Passos (2015), estudantes negras/os instalam no cotidiano das universidades vários desafios contemporâneos que requerem suas permanências, simbólicas e materiais, efetivas e com qualidade social. A autora demonstra como as ações afirmativas instauram reconfigurações curriculares que forçam a "revisão do eurocentrismo subalternizante e absoluto que marca a vida universitária brasileira" e, ainda, acionam que "já não é mais possível se ver somente como acadêmico, mas como um acadêmico pertencente a um determinado grupo étnico-racial, que teve, até então, ou muitas ou poucas oportunidades" (PASSOS, 2015, p. 176).

Assim, a presença de estudantes negras/os tem tensionado os campie o modus operandi curricular das universidades. Organizadas/os em coletivos e movimentos sociais, grupos e núcleos de estudos, em presença ativa nas salas de aula, as/os estudantes negras/os que adentram ao ensino superior têm proposto e demandado que as referências sejam enegrecidas, como fizemos e relatamos abaixo.

\title{
INSTIGANDO O ENEGRECIMENTO DAS REFERÊNCIAS
}

Por que temos um reduzido número de autoras/es negras/os em nossas bibliografias? E por que temos um elevado número de autoras/es brancas/os em nossas bibliografias? Essas são algumas questões que nos instigam e acompanham no ambiente acadêmico, perpassando salas de aula, ementas das disciplinas e as prateleiras das bibliotecas. Externalizamos nossas inquietações propondo um diálogo com a comunidade acadêmica da UFV, por meio da construção e realização do minicurso "Enegrecendo as referências: epistemicídio, descolonização e intelectuais negras/os". A partir do enegrecer e com o intuito de ser construído de forma coletiva, o minicurso colocou-se como parte das ações trazidas por sujeitos que compõem o Movimento 
Negro e passam a acessar o ensino superior, reivindicando uma perspectiva epistemológica antirracista.

Na sala onde realizamos o minicurso, a recepção das/os participantes se deu por meio de uma instalação artístico-pedagógica ${ }^{6}$ que montamos com cartazes questionadores relacionados à temática, livros de autoras/es brancas/os sobre as mesas e livros escritos por intelectuais negras/os no chão. Estes foram encapados com papel branco e colocados no interior de um espaço circundado por uma fita, cujo objetivo foi o de simbolizar um "sepultamento", o epistemicídio do conhecimento escrito pelas mãos negras.

Disponibilizamos livros escritos por negras/os e brancas/os, de diferentes áreas das ciências humanas e registros (como acadêmicos e literários). Também cuidamos de apresentar livros cujo conteúdo e temática dialogam entre si, como as obras "Segundo Sexo" e "Mulheres Raça e Classe", escritas respectivamente pelas filósofas Simone de Beauvoir (branca) e Angela Davis (negra), assim como de "Necropolítica" e "Nascimento da Biopolítica", obras, respectivamente, do filósofo camaronês Achille Mbembe (negro) e do filósofo francês Michel Foucault (branco).

Após percorrerem a instalação artístico-pedagógica, as/os participantes foram convidadas/os a expressar, por meio de uma palavra ou pequena frase, qual seria a motivação para o reduzido número de autoras/es negras/os nas bibliografias utilizadas na universidade, ao mesmo tempo que autoras/es brancas/os são priorizados. As respostas foram escritas nos envelopes brancos do chão, sem que as/os participantes soubessem ainda que em seu conteúdo se encontravam os livros das/os autoras negros.

A partir da reflexão inicial, problematizamos ainda: quais são as nossas referências, ou melhor, em quem nos referenciamos? Quais são suas posições geopolíticas? Quem e quais são os corpos teóricos que utilizamos? Tais questionamentos são inspirados em Alex Ratts (2018), ao sugerir que a expressão "corpo" no ambiente acadêmico seja compreendida para além de metáforas para denominar corpos discente, docente e teórico. Devemos nos atentar para o fato de que esses corpos são "marcados em variados e distintos processos de racialização, etnicização, generificação, sexualização, segregação e exploração" (RATTS, 2018).

No momento da apresentação pessoal das/os participantes, observamos a diversidade das graduações que cursavam, pois em outras experiências notamos que esses espaços eram predominantemente compostos por estudantes ligados a ciências humanas e sociais. Contudo, nesse encontro nos deparamos com alunas/os de cursos das ciências exatas e biológicas e da saúde, o que nos permitiu refletir sobre os tensionamentos cotidianos gerados pela presença de sujeitos negros no ensino superior, capazes de impulsionar para a busca e construção de outras epistemologias.

Percebemos nas palavras e frases escritas pelas/os participantes como o reduzido número de negras/os como referências e, por conseguinte, a elevada quantidade de brancas/os, indica a operacionalização e conformação do racismo epistêmico e do epistemicídio, como refletimos na introdução. Durante o minicurso trouxemos esses conceitos buscando costurá-los à noção de pedagogia das ausências de Gomes (2017), pensando na necessidade de reconhecer a produção das ausências no tocante às contribuições de negras/os para a construção do conhecimento.

Em meio às tramas moldadas pelo epistemicídio, destacamos o protagonismo do Movimento Negro brasileiro para a supressão das lacunas propositalmente 
(re)produzidas em decorrência do racismo, assim como na criação das alternativas para que as vozes negras sejam cada vez mais ouvidas nos lugares onde até então foram silenciadas e apartadas, como é o caso do ambiente universitário. Nesse caminhar, apresentamos o Movimento Negro como um "pedagogo emergente" que propôs uma série de políticas no campo educacional com intuito de combate ao racismo no país, enfatizando a lei 10.639/03. Acenamos para a necessária construção de uma "pedagogia das emergências", uma tentativa de evidenciar o que ainda não foi reconhecido em nossa história pela cultura dominante e descolonização dos saberes (GOMES, 2017).

Para propor o desmantelamento das amarras do epistemicídio, conduzimos as/os participantes para a remoção dos envelopes que encobriram os livros, escritos por intelectuais negras/os. Retiramos a fita que delimitava o espaço dos livros e simbolizava a tentativa de isolamento desses teóricos no campo acadêmico e solicitamos às/aos participantes que colocassem os livros de autoras/es negras/os e brancas/os juntos sobre a mesa, pois entendemos que o enegrecimento das referências não se refere à exclusão do conhecimento dominante, mas propõe a inclusão de conhecimentos negligenciados, a fim de abrirmos a possibilidade para formas dialógicas de produção do conhecimento.

No folhear dos livros, em poucos minutos, as/os participantes compartilharam leituras em voz alta de trechos de Angela Davis, Achille Mbembe, Allan da Rosa, Conceição Evaristo entre outras, que propuseram refletirmos como o conhecimento e acesso a essas produções engrandece nossas formas de olhar o mundo, entender a si mesmo/a e entender as/os outras/os. Nisso importa que não basta conhecermos o conteúdo de nossas referências bibliográficas, os textos e livros pura e simplesmente, mas apreender suas autorias. Por fim, apresentamos a biografia e as principais obras de algumas/uns autores/as das áreas de conhecimento nas quais atuamos, como a Educação, História, Ciências Sociais e Artes.

\section{CONSIDERAÇÕES FINAIS}

Diante do racismo, das desigualdades e discriminações raciais, o Movimento Negro, em suas lutas centradas na educação formal, demandou ao Estado brasileiro a constituição de políticas de promoção da igualdade racial. Argumentamos ao longo do texto que, no bojo dessas políticas implementadas desde o início do século XXI, notadamente da obrigatoriedade do ensino da história e cultura afro-brasileira e africana na educação básica e superior, e da reserva de vagas para negras/os no ensino superior, forjou-se um clima favorável e oportuno para o combate ao epistemicídio nas universidades brasileiras.

Diante da entrada de sujeitos negros nas universidades e da necessidade de reconhecer e valorizar a história e cultura afro-brasileira no âmbito educacional, há um tensionamento nos/dos referenciais bibliográficos lidos, citados e refletidos no ensino superior. Constatar a hegemonia de brancas/os permite reivindicar o enegrecimento das referências e garantir as presenças de negras/os nos espaços de produção científica.

Ressaltamos que a presença destes/as não pode estar confinada somente às temáticas das relações étnico-raciais, mantendo assim a perspectiva que responsabiliza 
CARMO, M. A. do; CORNÉLIO, B. G.; RODRIGUES, L. F.; FREITAS, M. S

apenas sujeitos negros pela produção antirracista. A dificuldade de diferenciar autoria (intelectuais negras/os) de temática (relações étnico-raciais) se dá por ambas as dimensões serem historicamente silenciadas, sub-representadas e, na sua grande maioria, excluídas do ambiente acadêmico e escolar.

Assim, ao reivindicar o acesso de negras/os ao ensino superior, o Movimento Negro oportunizou mudanças significativas quanto ao acesso, ultrapassou as perspectivas de formação desses sujeitos e considerou os tensionamentos gerados por suas presenças nos espaços hegemônicos. Minicursos, disciplinas, coletivos, eventos passam a ser exemplos de ações construídas a partir da presença negra que não só acessa o ensino superior, como também questiona e reinventa o modelo vigente.

Os diálogos, produzidos pelo minicurso fomentador deste artigo, mobilizam a necessidade de construir uma educação capaz de ouvir diferentes vozes. A partir das potencialidades geradas no espaço, apresentamos possíveis entrelaçamentos entre pesquisadoras/es negras/os e não-negras/os no meio universitário, com o intuito de trazer mais inquietações que respostas prontas acerca da temática levantada. Entendemos a urgência de enegrecer referências e pensamos que para trançar referenciais enegrecidos é preciso nos localizarmos geopoliticamente como produtores de conhecimento, pensar nas artimanhas do racismo e no engendramento do colonialismo que matou e ainda mata conhecimentos.

Artigo recebido em: 20/08/2020

Aprovado para publicação em: 18/11/2020

BLACKING THE REFERENCES: POSSIBLE INTERVENTIONS OF THE BLACK MOVEMENT IN BRAZILIAN EDUCATION

ABSTRACT: This article aims to present some contributions of the Black Movement for education, based on the bibliographic review and dialogues created in the mini-course "Blackening the references: epistemicide, decolonization and intellectual black people". We seek to analyze possible forms of intervention by the Black Movement in education and the minicourse is a materialization of the discussions to face the erasure of black intellectuals of bibliographical references. We found that, with the ingress of black individuals in Universities and the necessity to recognize and value history of Afro-Brazilian culture in the educational field, there is a conflict in the bibliographic references read, cited and reflected and dialogues produced by the minicourse expose the necessity to build an anti-racist education.

KEYWORDS: Black Movement. Education. Epistemicide.

ENNEGRECER DE LAS REFERENCIAS: POSIBLES INTERVENCIONES DEL MOVIMIENTO NEGRO EN LA EDUCACIÓN BRASILEÑA

RESUMEN: Este artículo tiene como objetivo presentar algunas contribuciones del Movimiento Negro Brasileño a la educación, a partir de experiencias y dos diálogos llevados a cabo en la 
realización del mini-curso "Ennegreciendo las referencias: epistemicidio, descolonización e intelectuales negros". Buscamos analizar posibles formas de intervención del Movimiento Negro en la educación y / o un curso corto en la materialización de discusiones para confrontar o extinguir intelectuales negros / referencias bibliográficas. Encontramos que, con el ingreso de los negros en las universidades, es necesario repensar y valorar la historia y la cultura afrobrasileña fuera del campo educativo, hay tensión en nosotros / dos referencias bibliográficas válidas, citadas y repetidas y que los diálogos producidos por el mini-curso, movilización por la necesidad de construir una educación antirracista.

PALAVRAS CLAVE: Movimiento Negro. Educación. Epistemicida.

\section{NOTAS}

1 - Consiste em um evento institucional que ocorre anualmente e abrange os campi UFV Viçosa, UFV Florestal e UFV Rio Paranaíba. O evento propõe a apresentações de trabalhos por estudantes do ensino médio e superior, bem como abre espaço para a realização de minicursos, palestras, seminários e atividades artísticas.

2 - De acordo com Maria Aparecida Bento (2002, p. 1-2): “Considerando (ou quiçá inventando) seu grupo como padrão de referência de toda uma espécie, a elite fez uma apropriação simbólica crucial que vem fortalecendo a auto-estima e o autoconceito do grupo branco em detrimento dos demais, e essa apropriação acaba legitimando sua supremacia econômica, política e social".

3 - Antes da normativa federal, as iniciativas de ação afirmativa nas universidades ocorreram seja por meio de leis estaduais (como foi o caso das universidades estaduais do Rio de Janeiro) ou por iniciativas locais através da autonomia dos conselhos universitários (como a Universidade de Brasília).

4 - Atualmente, em razão da lei. 13.409/16, o sistema de cotas acrescenta a reserva de vagas para pessoas com deficiência.

5 - Tradução livre: “Um problema é que, no século XXI, o racismo nem sempre é expresso de maneira aberta, mas sobreposta; em muitos casos, é inconsciente. (...) Existem outros, mais sutis, associados à negação do valor do conhecimento, das línguas, dos modos de produção do conhecimento e das modalidades de aprendizagem, valores, visões de mundo, histórias e propostas de povos indígenas e afrodescendentes. Isso se expressa em sua exclusão dos planos de estudo em geral e nas bibliografias dos assuntos da grande maioria das universidades e outros tipos de instituições de ensino superior da região, em todos os graus".

6 - Estas podem ser entendidas como "espaços metodológicos, criativos e dinamizadores de diálogos e socializações e que provoquem os sentidos para determinado tema e que serão o ponto de partida para a discussão de sentires e saberes sobre o que podem representar". Disponível em: http://www.itcp.ufv.br/?informativos=instalacoes-artistico-pedagogicaseconomia-solidaria-na-troca-de-saberes.

\section{REFERÊNCIAS}


CARMO, M. A. do; CORNÉLIO, B. G.; RODRIGUES, L. F.; FREITAS, M. S.

ALBERTI, Verena. Algumas estratégias para o ensino de história e cultura afro-brasileira. In. PEREIRA, Amílcar Araújo; MONEIRO, Ana Maria. Ensino de história e culturas afrobrasileiras e indígenas. Rio de Janeiro: Pallas, 2013.

BENTO, Maria Aparecida Silva. Branqueamento e branquitude no Brasil. In: CARONE, Iray; BENTO, Maria Aparecida Silva (orgs). Psicologia social do racismo - estudos sobre branquitude e branqueamento no Brasil. Petrópolis, RJ: Vozes, 2002, p. (25-58).

BRASIL. Lei no 10.639, de 9 de janeiro de 2003. Altera a lei no 9.394, de 20 de dezembro de 1996, que estabelece as diretrizes e bases da educação nacional, para incluir no currículo oficial da rede de ensino a obrigatoriedade da temática "História e Cultura Afrobrasileira", e dá outras providências. Diário Oficial da União, Brasília, 2003.

BRASIL. Lei no 12.711, de 29 de agosto de 2012. Dispõe sobre o ingresso nas universidades federais e nas instituições federais de ensino técnico de nível médio e dá outras providências. Diário Oficial da União, Brasília, 2012.

BRASIL. Lei n. 13.409, de 28 de dezembro de 2016. Altera a lei $n$. 12.711, de 29 de agosto de 2012, para dispor sobre a reserva de vagas para pessoas com deficiência nos cursos técnico de nível médio e superior das instituições federais de ensino. Diário Oficial da União, Brasília, 2016.

BRASIL. Lei n. 9.394, de 20 de dezembro de 1996. Estabelece as diretrizes e bases da educação nacional. Diário Oficial da União, Brasília, 1996.

CARNEIRO, Sueli. A construção do outro como não-ser como fundamento do ser. Tese (Doutorado em Educação) - FEUSP, São Paulo, 2005.

FONSECA, Marcus Vinícius. A população negra no ensino e na pesquisa em História da Educação no Brasil. In. FONSECA, Marcus Vinícius; BARROS, Surya Aaronovich Pombo de. (orgs). A história da educação dos negros no Brasil. Niterói: EdUFF, 2016, p. 23-50.

FONSECA, Selva Guimarães. Abordagens historiográficas recorrentes no ensino fundamental e médio. In: Didática e prática de ensino de história: experiências, reflexões e aprendizados. Campinas: Papirus, 2008, p. 39-48.

GOMES, Nilma Lino. O Movimento Negro educador: saberes construídos nas lutas por emancipação. Petrópolis: Vozes, 2017.

GOMES, Nilma Lino. Relações étnico-raciais, educação e descolonização dos currículos. Currículos sem fronteiras, v. 12, n. 01, 2012.

JACCOUD, Luciana de Barros; BEGHIN, Nathalie. Desigualdades raciais no Brasil: um balanço da intervenção governamental. Brasília: IPEA, 2002.

MATO, Daniel. Educación Superior y Pueblos Indígenas y Afrodescendientes en América Latina. Tendencias, tensiones y desafios: propuestas para continuar avanzando. In: 
MATO, Daniel et al (coord.). Educación superior y pueblos indígenas y afrodescendientes en América Latina: políticas y experiencias de inclusión y colaboración intercultural. 1a ed. Sáenz Peña: Universidad Nacional de Tres de Febrero, pp. 21-74, 2018.

NASCIMENTO, Abdias. Projeto de lei n. 1.332, 1983.

NOGUERA, Renato. Afroperspectividade: por uma filosofia que descoloniza. In: Geledés, Instituto da Mulher Negra, 12/07/2015. Disponível em: https://www.geledes.org.br/afroperspectividade-por-uma-filosofia-que-descoloniza/ Acesso em 20 nov. 2020.

PEREIRA, Amilcar Araujo; MAIA, Jorge Lucas; LIMA, Thayara Cristine Silva de. Os "rolês" do movimento negro brasileiro na atualidade, nas "pegadas" da educação. Revista do Instituto de Estudos Brasileiros, Brasil, n. 75, p. 162-183, abr. 2020.

RATTS, Alex. Os corpos teóricos e as teorias nos corpos. Eu preciso destas palavras, 2018. Disponível em: http://alexratts.blogspot.com/2018/08/as-teorias-nos-corpos.html. Acesso em: 07 mar. 2019.

SANTOS, Sales Augusto dos. A metamorfose de militante negros em negros intelectuais. Revista Mosaico, v. 3, n. 5, 2011.

SANTOS, Sales Augusto dos. Educação: um pensamento negro contemporâneo. Jundiaí: Paco Editorial, 2014.

SANTOS, Sales Augusto dos. O Sistema de Cotas para Negros da UnB: um balanço da primeira geração. Jundiaí, Paco Editorial: 2015.

SILVA, Petronilha Beatriz Gonçalves da. Diretrizes curriculares nacionais para a educação das relações étnico-raciais e para o ensino de História e Cultura Afrobrasileira e Africana. Conselho Nacional de Educação/Conselho Pleno/DF. Aprovado em 10/03/2004.

SILVA, Vanessa Patrícia Machado. O processo de formação da lei de cotas e o racismo institucional no Brasil. Dissertação (Mestrado em Sociologia). Programa de PósGraduação em Sociologia, Universidade Brasília, 2017.

Monalisa ApareCidA do CARMO: Doutoranda em Educação pela Universidade Estadual de Campinas (UNICAMP). Mestra em Educação e Graduada em História pela Universidade Federal de Viçosa (UFV). Professora substituta no Departamento de Educação, curso de Licenciatura em Educação do Campo - Ciências da Natureza 
CARMO, M. A. do; CORNÉLIO, B. G.; RODRIGUES, L. F.; FREITAS, M. S

(LICENA - UFV). Integrante do Núcleo de Estudos Afro-brasileiros de Viçosa (NEABViçosa) e do Grupo de Estudos e Pesquisas em Educação, Gênero e Raça (Educagera UFV).

Orcid: https://orcid.org/0000-0002-3573-0172

Email:monalisacarmo3@gmail.com

BeAtriz Gomes Cornélio: Mestra em Educação e graduada em Pedagogia pela Universidade Federal de Viçosa (UFV). Integrante do Núcleo de Estudos Afro-brasileiros (NEAB-Viçosa) e do Grupo de Estudos e Pesquisas em Educação, Gênero e Raça (Educagera - UFV).

Orcid: https://orcid.org/0000-0002-1253-0442

Email:somesc.beatriz@smail.com

Lillian FerReIRA Rodrigues: Mestranda em Educação e graduada em Pedagogia pela Universidade Federal de Viçosa (UFV). Professora da educação básica na prefeitura municipal de Ervália (PME), Minas Gerais. Integrante do Grupo de Estudos e Pesquisa em Educação, Gênero e Raça (Educagera - UFV).

Orcid: https://orcid.org/0000-0003-4155-0757

Email: lillianrodrigues19@gmail.com

Matheus Silva Freitas: Mestrando em Educação na Universidade Federal de Minas Gerais (UFMG). Graduado (licenciatura e bacharelado) em Ciências Sociais pela Universidade Federal de Viçosa (UFV). Integrante do Núcleo de Estudos Afro-Brasileiros (NEAB Viçosa) e do Grupo de Estudos e Pesquisas em Educação, Gênero e Raça (Educagera - UFV).

Orcid: http://orcid.org/0000-0001-6245-9085

E-mail: freitassmat@smail.com

Este periódico utiliza a licença Creative Commons Attribution 3.0, para periódicos de acesso aberto (Open Archives Iniciative - OAI).

Inter-Ação, Goiânia, v.46, n.1, p. 80-94, jan./mar. 2021. Disponível em: <http://dx.doi.org/10.5216/ia.v45i3.65156>. 